\title{
Kinetics of the thermal decomposition of pine needles
}

\author{
Alok DHAUNDIYAL, ${ }^{1 *}{ }^{*}$ itendra GANGWAR ${ }^{2}$ \\ ${ }^{1}$ Mechanical Engineering Department, Himgiri Zee University, India \\ e-mail: alok.dhaundiyal@hzu.edu.in (*corresponding author) \\ ${ }^{2}$ Applied Mechanics Department, Indian Institute of Technology, India
}

Manuscript received March 15, 2015; revised April 15, 2015; accepted May 20, 2015

\begin{abstract}
A kinetic study of the pyrolysis process of pine needles was examined using a thermogravimetric analyser. The weight loss was measured in nitrogen atmosphere at a purge flow rate of $100 \mathrm{ml} / \mathrm{min}$. The samples were heated over a range of temperature of $19^{\circ} \mathrm{C}-600^{\circ} \mathrm{C}$ with a heating rate of $10^{\circ} \mathrm{C} / \mathrm{min}$. The results obtained from the thermal decomposition process indicate that there are three main stages: dehydration, active and passive pyrolysis. The kinetic parameters for the different samples, such as activation energy and pre-exponential factor, are obtained by the shrinking core model (reaction-controlled regime), the model-free, and the first-order model. Experimental results showed that the shrinking model is in good agreement and can be successfully used to understand degradation mechanism of loose biomass. The result obtained from the reaction-controlled regime represented actual values of kinetic parameters which are the same for the whole pyrolysis process; whereas the model-free method presented apparent values of kinetic parameters, as they are dependent on the unknown function $\phi(C)$, on the sum of the parameters of the physical processes, and on the chemical reactions that happen simultaneously during pyrolysis. Experimental results showed that values of kinetic constant from the first-order model and the SCM are in good agreement and can be successfully used to understand the behaviour of loose biomass (pine needles) in the presence of inert atmosphere. Using TGA results, the simulating pyrolysis can be done, with the help of computer software, to achieve a comprehensive detail of the devolatilization process of different types of biomasses.
\end{abstract}

Keywords: thermal decomposition, thermogravimetric analysis, kinetic models, pyrolysis, biomaterial, kinetic models 


\section{Introduction}

The pines are coniferous, evergreen, resinous trees belonging to the genus Pinus of the family Pinaceae, native to the northern hemisphere. They are also found in South-East Asia and the Himalayan regions of India. The Chir pine (Pinus roxburghii) is predominant in the coniferous forests of the Himalayan regions of Uttarakhand and Himachal [1]. They constitute the major portion of the litter in coniferous forests [2].

Pine needles are abundantly found as underexploited biomass in coniferous forests and are responsible for forest fires and air pollution. According to the Forest Department of India, Dehradun, massive forest fires in 1995 engulfed 14.7 thousand acres of valuable forest area through 2,272 forest fire incidents in Uttarakhand, which created long-lasting ecological consequences [3]. Detrimental effects of fire make the top layer of the soil fallow and leave behind a layer of pine needles litter that prevents rain water from being absorbed by the soil, leading to the early depletion of the ground water cycle and stoppage grass growth, thus causing a scarcity of food for the livestock. Its tremendous potential as a combustible fuel for thermal as well as power application was studied through TGA (thermogravimetric analysis).

As forest residual logging, it would be wasteful to render the energy content of pine needles to a dump especially during times of increasing energy dependence. In addition, a higher level of utilization of pine needles would curtail ecological damages in hill conditions, and consequently, slow down the depletion of fossil fuel reserves. Using biomass as fuel instead of fossil fuel mitigates $\mathrm{CO}_{2}$ emissions, as the evolved amount of $\mathrm{CO}_{2}$ during the combustion process is compensated by the amount of $\mathrm{CO}_{2}$ necessary for the photosynthesis process, hence it behaves as a $\mathrm{CO}_{2}$ neutral source of energy [4,5]. Thermal and power generations are not only applications that biomass provides, but there are also several processes through which we utilize biomass for valuable products [6]. Biomass is a potential source for synthesizing the same chemical that is derived from crude oils. One of these processes is pyrolysis which belongs to the subgroups of thermo-chemical processes. In the pyrolysis process, the biomass decomposes into gases, liquid oils, and char. The information regarding pyrolysis and thermal analysis is studied in the papers of John E. White [7] and Paolo Ghetti [8]. Thermogravimetric analysis is often used for measuring mass losses and to know the mole fraction of evolved species during pyrolysis [9]. The main function of thermogravimetric analysis is online measurement of variations in mass as functions of time or temperature. Application of TGA is not confined to forestry or agricultural residual logging $[10,11]$, but also for thermal decomposition of other materials such as medical waste [12], sewage sludge [13, 14], and waste car tyres [15]. Residues of biomass, mainly char, after devolatilization depend on the type of biomass used. The thermal 
decomposition process is affected by operating parameters such as pressure, heat flow rate, temperature, and properties of biomass like moisture, bulk density, and composition. The bulk density of biomass influences the heat transfer into the particle and mass transfer from the particle. Hence, it is most significant to assure the best possible contact between particle and heating area [16, 17]. Various models regarding biomass decomposition are given, such as the isoconversional model that presumes kinetic parameters are inconstant during the process of decomposition but depend on conversion $[18,19]$. Another model is the lumped kinetic model, which considers an ultimate number of parallel decomposition of $\mathrm{n}$-th order reactions [20]. These partial reactions assist in complete decomposition run. As the pyrolysis process is the first thermo-chemical step in the gasification process, its chemical kinetics highly affect the yield of tar oil and char as well as their reactivity $[21,22]$.

Kinetic studies are very useful for the interpretation of reaction mechanism and catalytic phenomena, behaviour on molecular basis, optimization, and the development of new chemical processes as well as a gasifier design for bio-fuel extraction and simulation. In addition, the study of chemical reaction kinetics is of main interest to both chemists and the chemical engineering field. It can be used for elaborating rates data to attain various objectives [23]. The main significance of using kinetic analysis is to extract the valuable information on the pyrolysis steps through the different forms of kinetic models and their correlations. Eventually, it can be extrapolated to the industrial applications such as bio-fuel refineries. The pine forest tree is a resinous tree and easily catches fire. Its stability is maintained (or it does not decay) for many years due to the presence of a high percentage of lignin that provides strength to it. Therefore, we did a TGA analysis to know its thermal stability, its behaviour with inert gases, while the scope of using TGA results for simulating pyrolysis using computer software was to understand the devolatization of the different types of biomass.

\section{Materials and methods}

Pine needle samples for thermogravimetric analysis were taken from different altitude regions as: Dehradun (1,427 ft.), Teri Garhwal (5,740 ft.), and Champawat $(5,280 \mathrm{ft}$.) districts in Uttarakhand. Pyrolysis of pine needles was performed using the thermogravimetric equipment, SDT Q600 (TA, Perkin Elmer etc) and Alumina $\left(\mathrm{Al}_{2} \mathrm{O}_{3}\right)$ crucibles were used. A horizontal TG/DSC holder was used. Both DSC and TGC were performed to know the thermal as well as kinetics behaviour of loose biomasses. In order to achieve pyrolysis conditions, a nitrogen atmosphere was used. Nitrogen was used as the purge and protective gas protecting the microbalance against possible pollutants. The volumetric discharge rate of nitrogen was set to $100 \mathrm{ml} / \mathrm{min}$. for the purge gas. Thermogravimetric measurements were 
carried out at a heating rate of $10^{\circ} \mathrm{C} / \mathrm{min}$. The furnace zone had to be purged for 60 minutes in order to drive off all the remaining oxygen. The mass of samples was measured between 12 and $21 \mathrm{mg}$. These measured samples are sufficient for a good contact area between the crucible and the sample. To measure the actual sample and furnace temperatures, thermocouple types $\mathrm{R}$ (Platinum-Rhodium-13\%/ Platinum) were used.

The pine needles contained about $1.8 \mathrm{wt} \%$ of ash (on dry mass basis) during the pre-treatment of producer gas by heat exchanger and cyclone. The chemical analysis of pine needles was experimentally determined with the help of the CHNS-O analyser (Perkin Elmer 2400 Series), which is shown in Table 1.and Table 2.

Table 1. Proximate analysis and heating value of pine needle samples

\begin{tabular}{lccccc}
\hline \multicolumn{1}{c}{$\begin{array}{c}\text { Location } \\
\text { (Samples) }\end{array}$} & $\begin{array}{c}\text { Volatile } \\
\text { Matter } \\
(\%)\end{array}$ & $\begin{array}{c}\text { Ash } \\
\text { content } \\
(\%)\end{array}$ & $\begin{array}{c}\text { Moisture } \\
(\%)\end{array}$ & $\begin{array}{c}\text { Fixed } \\
\text { Carbon } \\
(\%)\end{array}$ & $\begin{array}{c}\text { HHV*(M } \\
\mathbf{J} / \mathbf{k g})\end{array}$ \\
\hline Teri & 73.1 & 2.1 & 10.2 & 14.6 & 20.7 \\
Garhwal & 68.4 & 2.1 & 11.6 & 17.9 & 20.8 \\
Rishikesh & 3.1 & 21.5 & 17.1 & 20.2 \\
Champawat & 58.3 & & &
\end{tabular}

*High heating value (HHV) at constant volume

Table 2. Ultimate analysis of pine needle samples

\begin{tabular}{lccccc}
\hline $\begin{array}{c}\text { Location } \\
\text { (Samples) }\end{array}$ & $\mathbf{C} \%$ & $\mathbf{H} \%$ & $\mathbf{O} \%$ & $\mathbf{N} \%$ & $\mathbf{S} \%$ \\
\hline Teri & 54.05 & 5.34 & 32.58 & 0.56 & 0.19 \\
Garhwal & 53.64 & 5.36 & 33.92 & 0.62 & 0.20 \\
Rishikesh & 53.36 & 5.91 & 31.77 & 0.61 & 0.17 \\
\hline Champawat & & & & & \\
\hline
\end{tabular}

Pyrolysis of pine needles

Various complex reactions are involved in biomass pyrolysis, which result in a large number of intermediates and products; hence, proposing an appropriate reaction mechanism and modelling the kinetic behaviour is extremely complicated. Nevertheless, it can be performed based on visible kinetics, which also urges researchers to propose a much more precise mechanism involving available experimental utilities. Usually, it is cumbersome to formulate an accurate mechanism which takes into account several experimental parameters and miscellaneous feedstock. All the mechanisms can be depicted by a simplified general method wherein our loose biomass as feedstock is transformed into 
gaseous materials or volatiles, blackish tar, and char as the primary feedstock or end product for bio-refineries to transform it into bio fuels [24]. Solid char is formed in the temperature range of $200-400^{\circ} \mathrm{C}$ in the primary decomposition phase (however, it depends on the type of biomass one is using) and, consequently, it reacts at temperatures over $400^{\circ} \mathrm{C}$, which is the second pyrolysis phase [25].

The main component of biomass is cellulose, which is often used as its model compound as of its simpler structure. An incipient mechanism of cellulose pyrolysis, the two-step competitive mechanism, shows cellulose transformation into volatiles in the first step and char evolution with gases in the second one was developed by Broido [26]. Antal and Varhegyi proposed to use the one-step reaction mechanism of the first-order reaction equation to show cellulose pyrolysis $[27,28]$. Finally, it was concluded that complicated models including more than one reaction step are not necessary to be simulated with the rate-limiting step, the depolymerization of cellulose. Depolymerization can be clearly shown by the onestep mechanism of the first-order reaction equation with high activation energy [29]. However, this simplification seems inexact as the composition of light gases in pyrolytic mixtures $[30,31]$ proves that cellulose pyrolysis involves at least two reaction steps. These steps have to be competitive since the yield clearly depends on the heating rate. Although the postulation of two competitive reaction steps is not novel, it has been continuously modified and clarified [32]. The most important contribution has been done by bringing the so-called "active cellulose" or "intermediate" into the reaction chain $[33,34]$. The multi-step lumped mechanism is shown in Figure 1.

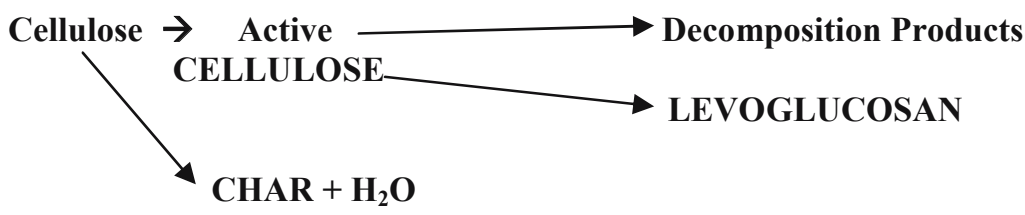

Figure1. Multi-step lumped mechanism of cellulose pyrolysis

\section{The theory of kinetic modelling}

Mainly, there are two types of methods used in kinetic modelling: model-free and shrinking core model (SCM, model-fitting method). The model-free approach implies that the estimation of kinetic parameters can be done without assuming a reaction model. Principally, there are two types of methods used in kinetic analysis: the so-called model-free and the model-fitting method. One of the methods is isoconversional, which usually uses model-free methods [35,36]. According to the isoconversional principle, the reaction rate at a constant extent of conversion is a function of temperature only and the resulting kinetic parameters are dependent on 
the conversion. The mostly used differential isoconvesional method is the Friedman method [37]. Model-fitting methods use a particular reaction model to obtain the best fit of experimental data resulting in the determination of kinetic parameters.

Each model-fitting algorithm implies minimization of the difference between the experimental and the calculated reaction rate values. A wide variety of reaction models is mentioned in the project of the ICTAC kinetics committee [38] together with appropriate model selection recommendations. Relating to an ICTAC kinetic study [39], reliability of the model-fitting methods is comparable with that of the model-free isoconversional methods if the fitting procedure is used simultaneously for multi-heating rates. The models used are discussed below.

\section{Shrinking core model}

The shrinking core model was first presented by Yagi and Kunii [40]. The various practical cases such as, fluid-solid reactions can be approximated as the first-order for mathematical simplicity [41]. This model should be employed for the first-order reactions and considers whether the rate of leaching process is controlled by the diffusion of the reactant or the rate of the surface chemical reaction. The heterogeneous leaching reaction can be shown as follows:

$$
\mathrm{A}_{\text {fluid }}+\mathrm{B}_{\text {solid }} \rightarrow \text { Fluid product }+ \text { Solid products }
$$

The shrinking core model for an isothermal spherical particle is divided into three steps: diffusion of reactant $A_{\text {fluid }}$ from the main body of gas film to the surface of the solid, reaction on the surface between reactant $A_{\text {fluid }}$ and solid, diffusion of reaction products from the surface of the solid through the gas film back into the main body of the gas. A detailed integrated forms of kinetic laws $(\phi(\mathrm{C}))$ for different control regimes is detailed in Table 3 [42].

In this model, the ash layer was absent and did not contribute to any resistance. Generally, the shrinking core model is used in the incineration process. The reaction mechanism, in the case of SCM, postulates that the reaction be carried out on the surface of a spherical solid particle [43]. The shrinking core model divided the control regimes into three parts what is shown in Table 3.

Table 3. Control regimes according to the shrinking core model (SCM)

\begin{tabular}{lllc}
\hline \multicolumn{1}{c}{ Control regimes } & \multicolumn{1}{c}{$\boldsymbol{\phi}(\mathbf{C})$} & \multicolumn{1}{c}{$\mathbf{k}_{\mathbf{s}}$} & Equation \\
\hline Liquid film diffusion & $1-(1-\alpha)^{2 / 3}$ & $2 \mathrm{bDk}_{\mathrm{d}} \mathrm{C}_{\mathrm{A}} / \rho \mathrm{R}_{0}{ }^{2}$ & 1 \\
\hline Solid product diffusion & $1-3(1-\alpha)^{2 / 3}+2(1+\alpha)$ & $2 \mathrm{bDk}_{\mathrm{d}} \mathrm{C}_{\mathrm{A}} / \rho \mathrm{R}_{0}$ & 2 \\
\hline Chemical reaction & $1-(1-\alpha)^{1 / 3}$ & $2 \mathrm{bDk}_{\mathrm{c}} \mathrm{C}_{\mathrm{A}} / \rho \mathrm{R}_{0}{ }^{2}$ & 3 \\
\hline
\end{tabular}


Note: Where $\mathrm{k}_{\mathrm{c}}$ means the apparent rate constant (reaction rate constant when the chemical reaction is rate controller for the shrinking core model, which depends on temperature and gaseous reagent concentration). We used equation (3) only in our kinetic analysis.

$\phi(C)$ : Reaction model; b: Stoichiometric coefficient of reaction; D: diffusion coefficient in the porous product layer; $\mathrm{C}_{\mathrm{A}}$ : Concentration of the leaching agent; $\rho$ : Density of the solid particle; $\mathrm{R}_{0}$ : Radius of the unreacted particle; $\mathrm{k}_{\mathrm{s}}$ : Reaction rate constant; $\alpha$ : conversion factor; $\mathrm{k}_{\mathrm{d}}$ : reaction rate constant when diffusion is rate controller.

The kinetic parameters E (activation energy) and A (pre-exponential factor) can be obtained by using shrinking core model (SCM). If the integrated form of kinetic law i.e $\phi(\mathrm{C})=\mathrm{k}_{\mathrm{s}}$ is known, it can plot the values of $\phi(\mathrm{C})$ against time for different iso-thermal data points. Each of these plots should be linear, the slope being the value of apparent rate constant $k_{\mathrm{s}}$ at that temperature as the plot of $\ln (\mathrm{k})$ versus reciprocal temperature would be a straight line. The slope of straight line gives the value of $-\mathrm{E} / \mathrm{R}$, whereas intercepts provide $\ln (\mathrm{A})$. Regarding the $\mathrm{SCM}$ method, there is also an implicit assumption that the value of activation energy, $\mathrm{E}$ does not change during the course of reaction.

Based on the Arrhenius law for rate constant, rate constant can be expressed by the following equation

$$
\begin{aligned}
& \mathrm{k}=\mathrm{A} \exp (-\mathrm{E} / \mathrm{RT}) \\
& \ln (\mathrm{k})=\ln (\mathrm{A})-\mathrm{E} / \mathrm{RT}
\end{aligned}
$$

\section{The model-free method}

The model-free differential isoconversional method was used to provide the apparent kinetic parameters. Integral approach fails to estimate activation energy $\mathrm{E}$ if the $\phi(\mathrm{C})$ is unknown [44]. Moreover, in SCM, it was assumed that evaluated E does not change during the reaction. On the contrary, in the model-free approach, the activation energy should be accepted as a variable parameter; therefore, E can be calculated at a different level of $\mathrm{C}$. In general, the integral form of the rate equation is written as:

$$
\phi(\mathrm{C})=\mathrm{kv} \mathrm{t}
$$

$\alpha=$ conversion or fractional mass remaining

$\mathrm{C}=\left(\mathrm{m}(\mathrm{t})-\mathrm{m}_{\mathrm{f}}\right) /\left(\mathrm{m}_{0}-\mathrm{m}_{\mathrm{f}}\right)$

$\alpha=\left(\mathrm{m}_{0}-\mathrm{m}(\mathrm{t})\right) /\left(\mathrm{m}_{0}-\mathrm{m}_{\mathrm{f}}\right)$

$1-\alpha=\mathrm{C}$ (fractional mass loss)

$\mathrm{m}(\mathrm{t})=$ instantaneous mass of sample

$\mathrm{m}_{\mathrm{f}}=$ final mass of sample or residue mass

$\mathrm{m}_{0}=$ initial mass of sample

$\mathrm{k}_{\mathrm{v}}=$ rate constant for model-free method 


$$
\begin{aligned}
& \phi^{\prime}(\mathrm{C}) \mathrm{dC} / \mathrm{dt}=\mathrm{k} \\
& \mathrm{dC} / \mathrm{dt}=\mathrm{kv} / \phi^{\prime}(\mathrm{C}) \\
& \mathrm{dC} / \mathrm{dt}=\mathrm{kv} \mathrm{F}(\mathrm{C})
\end{aligned}
$$

So, $\mathrm{F}(\mathrm{C})$ in the differential form of rate equation equals $1 / \phi^{\prime}(\mathrm{C})$. Invoke equation (5) and (9)

$$
\mathrm{dC} / \mathrm{dt}=\mathrm{A} \exp (-\mathrm{E} / \mathrm{RT}) \mathrm{F}(\mathrm{C})
$$

Assuming a fixed value of $\mathrm{C}$, equation (10) can be rewritten as follows:

$$
\begin{aligned}
& \int_{0}^{\mathrm{C}} \frac{\mathrm{dC}}{\mathrm{F}(\mathrm{C})}=\mathrm{A} \exp (-\mathrm{E} / \mathrm{RT}) \int_{0}^{\mathrm{c}} \mathrm{dt} \\
& 1 /\left(\mathrm{A} \exp \left(-\frac{\mathrm{E}}{\mathrm{RT}}\right)\right) \int_{0}^{\mathrm{c}} \frac{\mathrm{dC}}{\mathrm{F}(\mathrm{C})}=\mathrm{tc} \\
& \phi(\mathrm{c}) / \mathrm{Ac} \exp (-\mathrm{E} / \mathrm{RT})=\mathrm{tc}, \mathrm{i}
\end{aligned}
$$

$-\ln \mathrm{t}_{\mathrm{c}, \mathrm{i}}=\ln \left(\mathrm{A}_{\mathrm{c}} / \phi(\mathrm{c})\right)-\mathrm{E}_{\mathrm{c}} / \mathrm{RT}_{\mathrm{i}}$

In the equation (13), $\mathrm{i}$ in subscript refers to isothermal condition $\mathrm{t}_{\mathrm{c}, \mathrm{i}}$ is the time needed to reach a certain conversion isothermally, and $A_{c}$ and $\phi(c)$ represent the pre-exponential factors and the integrated form of the reaction model. For the fixed value of $\mathrm{C}$, it shows that a plot of the time against temperature in equation (13) would be a straight line; hence the value of $-\mathrm{E} / \mathrm{R}$ will be obtained. So, $\mathrm{E}$ can be calculated at different levels of $\mathrm{C}$.

Equation (6) can be modified in terms of temperature and conversion as follows:

if pyrolysis is carried out non-isothermally and temperature is the linear function of $\mathrm{t}$ (time), then:

$\mathrm{T}=\mathrm{T}_{\mathrm{o}}+\mathrm{Bt}$

$\mathrm{B}=\mathrm{dT} / \mathrm{dt}\left({ }^{\circ} \mathrm{C} / \mathrm{min}\right)$

$\mathrm{B}=$ linear heating rate

$$
\left(\frac{d m}{d t}\right)=\mathrm{k}_{\mathrm{c}} \mathrm{t}
$$

$$
-\int_{m_{0}-m_{f}}^{m_{(t)}-m_{f}} \frac{d m}{m}=\int_{0}^{t_{c}} k_{v} d t
$$

For first-order reaction,

$$
-\ln \mathrm{C}=\int_{0}^{\mathrm{t}_{\mathrm{c}}} \mathrm{k}_{\mathrm{v}} \mathrm{dt}
$$

The right-hand side of the equation (15) can be modified by $k_{v}=A_{C} \exp \left(-E_{C} / R T\right)$

$$
\ln C=-A C / B \int_{T_{0}}^{T} e^{-\frac{E_{C}}{R T}} d T
$$

In 1961, Vallet, in a trilingual monograph, makes the substitution [45].

$\mathrm{z}=-\mathrm{E}_{\mathrm{C}} / \mathrm{RT}$

and reduces integral equation (16) to that for the expression

$\ln \mathrm{C}=-\left(\mathrm{A}_{\mathrm{C}} \mathrm{E}_{\mathrm{c}} / \mathrm{R} \mathrm{B}\right) \int_{z}^{\infty} z^{-2} e^{-s} \mathrm{ds}$

$\mathrm{J}(\mathrm{z})=\int_{z}^{\infty} z^{-2} e^{-s} \mathrm{ds}=\mathrm{z}^{-2} e^{-s} \mathrm{~S}(\mathrm{z})$

$\ln \mathrm{C}=-\left(\mathrm{A}_{\mathrm{C}} \mathrm{E}_{\mathrm{c}} / \mathrm{R} \mathrm{B}\right) \mathrm{J}(\mathrm{z})$ 
Vallet evaluates the rapidly changing $\mathrm{J}(\mathrm{z})$ and the slowly varying $\mathrm{S}(\mathrm{z})(0.9564$ to 0.9633 ) for range of $\mathrm{z}$ from $0 \leq \mathrm{z} \leq 200$, thus covering various possible solutions for most problems.

In this way, we can obtain the value of $\ln (1-\alpha)$ for a simple first-order reaction. The order of reaction can be known by

$$
-\ln (d \alpha / d t)=-n \ln (1-\alpha)+\ln (1 / k)
$$

\section{Results and discussion}

\section{Pyrolysis of pine needles}

The thermal decomposition of pine needle samples is shown in Figure 2 $(\mathrm{a}-\mathrm{d})$. As it can be seen from the DTG curves, thermal degradation shows three peaks. The first one is up to about $55-67^{\circ} \mathrm{C}$ with a mass loss of about $1-1.5 \%$. The second one is in temperature interval of $300-305^{\circ} \mathrm{C}$ with 3 to $3.5 \%$ as mass loss, showing mostly the degradation of hemicelluloses. The third is found with mass loss of 5 to $5.5 \%$ at a temperature range of $340-350^{\circ} \mathrm{C}$. Before the decomposition of pine needles started, some water and air moisture had got evolved. The end of drying is done at around 49 to $80^{\circ} \mathrm{C}$. The process of biomass pyrolysis initiates above the upper limit of the given range, whereas, with wood, pyrolysis starts at $160^{\circ} \mathrm{C}$ [46]. The maximum mass loss of pine needles through pine needles decomposition cures (Figure $2(a)$ and Figure $2(d)$ ) corresponding to temperature and time is obtained at around $345-350^{\circ} \mathrm{C}$ within $1800-1920$ seconds. Temperature range was fixed below $600^{\circ} \mathrm{C}$. The main decomposition regime (active pyrolysis) is in the range of $200-380^{\circ} \mathrm{C}$ approximately for three samples collected at different altitude levels with a mass loss of $56 \%$. Above $387^{\circ} \mathrm{C}$, an iota of mass (passive pyrolysis) undergoes final decomposition. Mainly hemicelluloses and cellulose in loose biomass (pine needles) decompose in the primal stage of active pyrolysis. In this experiment, decomposition rate reached two maximums at $305^{\circ} \mathrm{C}$ and $345^{\circ} \mathrm{C}$, whereas lignin is decomposed in both stages. Passive pyrolysis which usually occurs at a very low decomposition rate, involves lignin decomposition. Although lignin degradation happens in the wide temperature interval of $160-600^{\circ} \mathrm{C}$ dichotomizing it from hemicellulose and cellulose decomposition is difficult. The peak complexity at higher heating rate usually occurs due to a relatively high content of hemicellulose degradation at lower temperatures as cellulose. It is obvious that carbon content in samples increase with temperature at the expense of decreasing fraction of hydrogen content in biomass. The pattern, which was experimentally found in Figure $2(a-d)$ clearly depicts that solid char is more charred due to the increasing temperature. In Figure $2(b)$, there can be seen a negligible increase in sample weight during experiment caused by the adsorption of gaseous reagents on 
the solid surface, or the interaction of a very small fraction of $\mathrm{CO}_{2}$ in the furnace with some components of a mineral layer (ash) of the char, which was observed during our studies of catalytic effects of ash in pyrolysis [47]. From Figure $2(b)$, the mass loss of samples begun at the temperature interval of 30 to $50^{\circ} \mathrm{C}$ and the maximum rate of change was observed at range of $300-400^{\circ} \mathrm{C}$. The final residue obtained in the end was about 27 to $28 \%$ of the initial mass of samples. In an inert atmosphere like argon and nitrogen, the rate of decomposition is very slow and it decreases slowly. Such a process is ascribed to the gradual devolatilization of the char produced at lower temperatures [48] or it can be identified as corresponding to transformations of a part of the initial sample. Relating to kinetic modelling, such behaviour either refers to a reaction in series or to an independent parallel reaction. Unlike inert gases, in air, an increase in the rate of decomposition has been seen due to the oxidation of char, so that almost no residual mass is left in the end. Such behaviour was observed by Bilbao et al. [49].

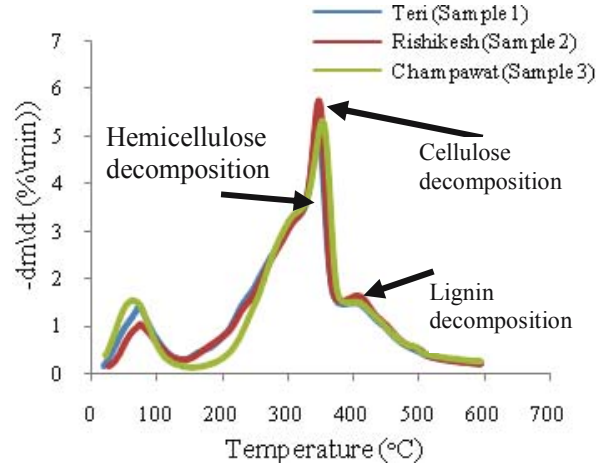

(a)

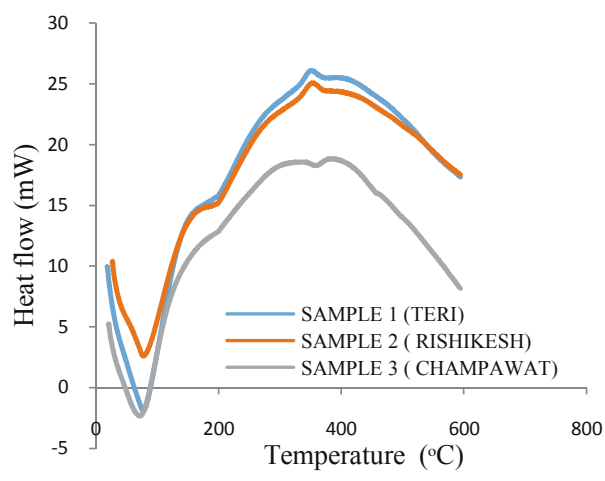

(c)

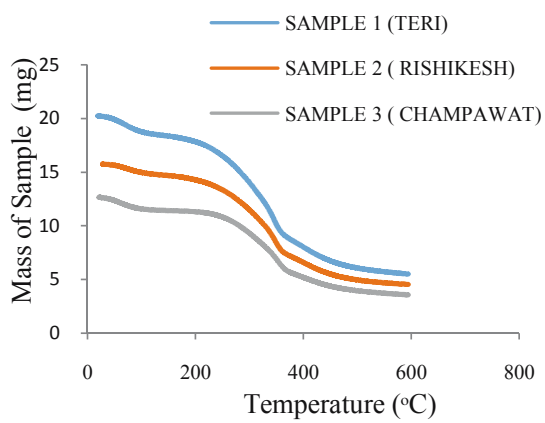

(b)

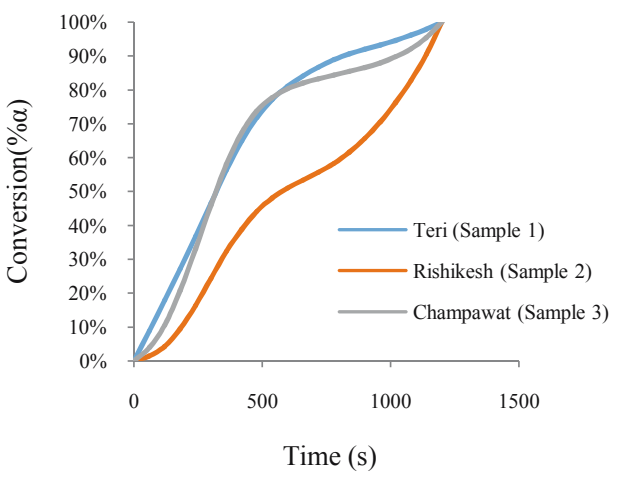

(d)

Figure $2(a-d)$.Curves for the thermal decomposition of pine needles

(TGA, DTG, and DSC) under inert atmosphere of nitrogen 


\section{Kinetics of thermal decomposition}

Figure $3(a-d)$ shows the variation of fraction mass remaining of different samples with time and temperature. Supposing that pyrolysis is a first-order reaction, the calculation of kinetic parameters is done with the help of two methods: model-free iso-conversional and shrinking core model. In the kinetic modelling of biomass pyrolysis, a pseudo-homogenous kinetic equation can be involved [50]. Thus, the simple pseudo-homogenous reaction model for the firstorder reaction with respect to pine needles as solid substrate can be used to predict the overall reaction rate. The reaction rate constants for the model-free as well as the shrinking core model are estimated from the experimental results as shown in Figure $3(\mathrm{a}-\mathrm{d})$. The values of the slopes in plots provide reaction rate constants, which are represented in equation (6) and equation (3).

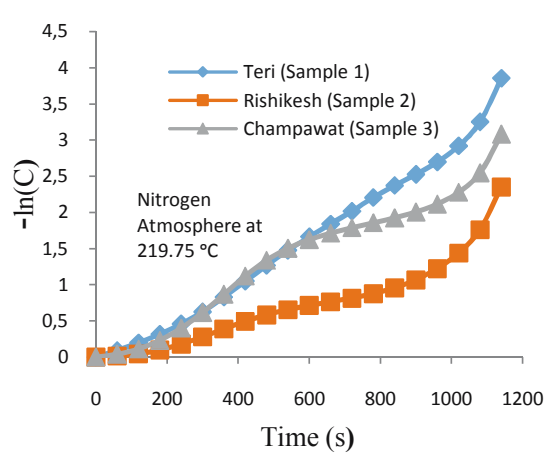

(a)

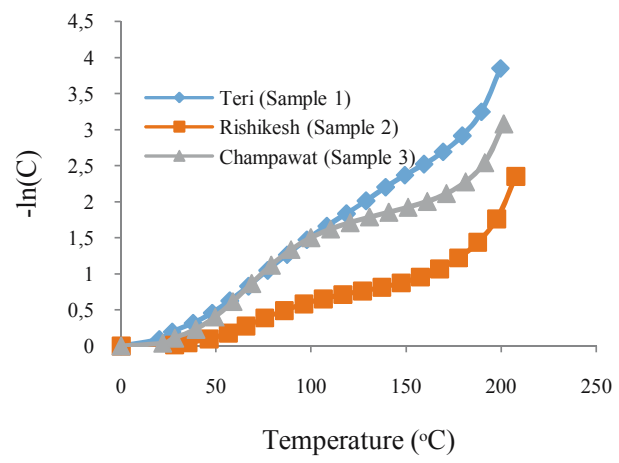

(c)

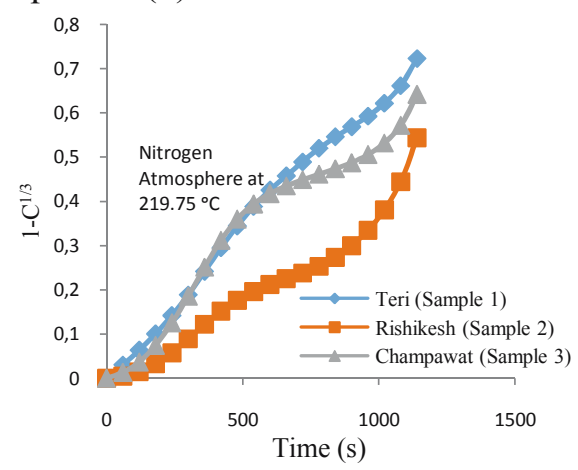

(b)

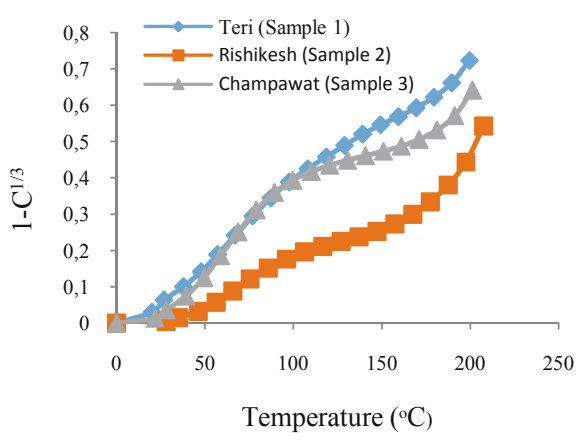

(d)

Figure $3(a-d)$. Graphical plot of the linearized kinetic models (first-order model $(\mathrm{a}, \mathrm{d})$ and the shrinking core model $(\mathrm{b}, \mathrm{d}))$ for pine needles under inert atmospheres of $\mathrm{N}_{2}$ with time and temperature 
The relationship between the left-hand sides of equation (15) and equation (3), separately, must show the linear behaviour with time in order to prove the validity of first-order and shrinking core models. The role of these two equations in the experimental results obtained for the pyrolysis of pine needles can be seen in Figure 3. An experimental range of conversion varied from 5.7E-4 to 0.99 for all the three samples in an inert atmosphere. The curve fitting of data presented in Figure 3 leads to the conclusion that the first-order reaction model can be applied only in the narrow range of conversion, whereas the shrinking core model relatively shows the good fitting of data points for the wide range of conversion. Having seen the curve fitting of data points, the validity of the first-order kinetics has likely indicated the pyrolysis of the pine needles proceeded, accordingly, to different mechanism. As it was seen in the results, the shrinking core models as well as the first-order model do not show a good agreement with the experimental data points at the higher rate of conversion. There is a likelihood that the limitation of diffusion can play a major role in this zone of conversion, which happened after $3300 \mathrm{~s}$. The physical as well as chemical properties, residence time of volatile gases, heating rate and temperature are some major parameters that affect the pyrolysis of biomass. The pyrolysis of biomass at high temperature results in decreased char yield, mainly due to gasification reactions occurring at higher temperature [51]. As it can be seen from Figure $3(b)$, the shrinking core model in the regime of chemically controlled reaction is applicable up to a certain maximum value of conversion only. The higher volatile content in needle samples reduces the pyrolytic conversion rate as with the increasing temperature range of 370 to $592^{\circ} \mathrm{C}$ char yield decreases. The decomposition of cellulose in loose biomass gives higher bio-char yield at temperatures below $302^{\circ} \mathrm{C}$. At temperatures above $302^{\circ} \mathrm{C}$, cellulose depolymerizes, resulting high volatile content [52]. In the case of a high heating rate, the residence time has an insignificant effect on biochar yield, and hence suppresses dehydration reactions and the formation of less reactive anhydrocellulose, which provides a higher yield of char [53]. Thus, the effect of heating rate is stronger in the pyrolysis of biomass than that of other fossil fuels. Higher pyrolysis temperature also resulted in more liquid cracking, which provides a higher yield of gaseous products and a lower yield of tar and char [54].

For all feedstock, large decreases in biochar yield were observed between the pyrolysis temperatures of $350^{\circ} \mathrm{C}$ and $500^{\circ} \mathrm{C}$ [55].

For the different volatile content, Sample 2 and Sample 3 have standard deviations of 0.01206 and 0.0120 respectively, whereas Sample 1 has the least standard deviation of 0.01 among the three samples.

Residence time at low temperature largely affects char yield rather than that of higher temperature. This is due to the fact that solid phase reactions are faster and therefore complete within 1 to $2 \mathrm{~s}$. Secondary pyrolysis usually occurs at $700^{\circ} \mathrm{C}$, but it has occurred earlier in the case of loose biomass, so the overall rate of 
reaction decreased. During secondary pyrolysis, the rate of reaction which is the amount reacted in relation to the initial amount, decreases as the amount of substrate decreases [56]. The secondary reactions usually take place at around $700-800^{\circ} \mathrm{C}$. These reactions occur mostly between the products of the primary reaction. The importance of secondary reaction increases with the residence time of volatile compounds in the hot zone of the reactor [57]. It can be concluded that high volatile and ash content reduce (first-order reaction) pyrolytic conversion rate at a higher temperature.

In Figure $4(b)$, at $335^{\circ} \mathrm{C}$, all pyrolysis had taken place, and hence the slopes for all the samples went vertical to the abscissa and reaction rate abruptly increased with temperature, which led to fast pyrolysis reaction. In Figure 2 (c), it can be also seen in DSC curves that there is a peak formation due to sudden increase in the heat of flow rate at the temperature range of $200-350^{\circ} \mathrm{C}$. Relating to the variation in heat flow, Lee et al. [58] provided a view relating to the heat of reaction during pyrolysis. They estimated experimentally the heat of reaction through conversion rate, solid temperature and thermal properties, pyrolysis gas composition and pressures. It was found for an incident heat flux of $31.92 \mathrm{~kJ} / \mathrm{m}^{2} \mathrm{~s}$ provided parallel to the grain direction, the pyrolytic region can be classified into three zones: an endothermic primary degradation occurs below $250^{\circ} \mathrm{C}$, whereas an exothermic partial zone varies from $250^{\circ} \mathrm{C}<\mathrm{T}<340^{\circ} \mathrm{C}$; and an endothermic surface char zone from $340^{\circ} \mathrm{C}<\mathrm{T}<520^{\circ} \mathrm{C}$.

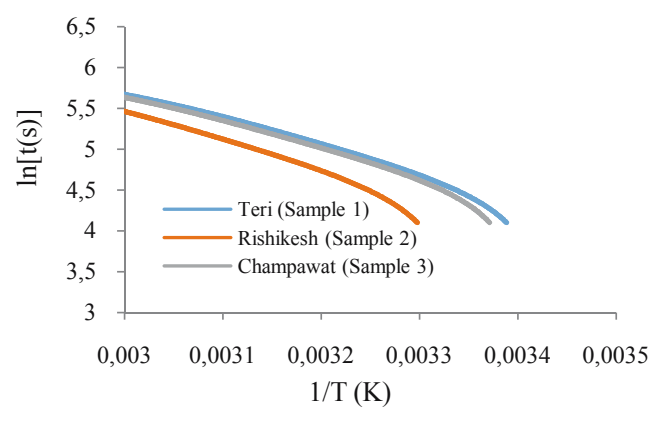

(a)

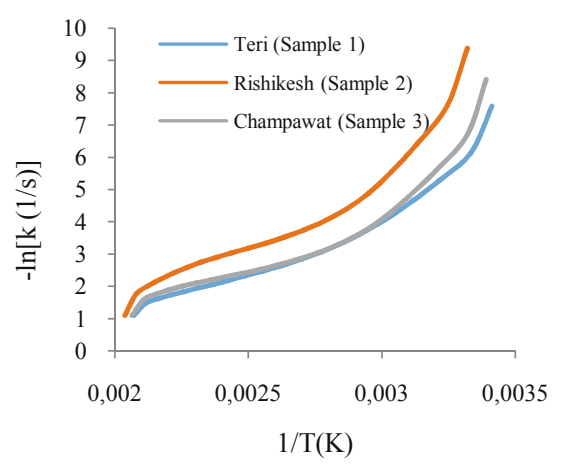

(b)

Figure $4(a-b)$. Arrhenius plots for pine needle pyrolysis in nitrogen atmosphere

Kinetic parameters obtained for the better-fitting models from the slope of straight line in Figure $3(a-d)$, are shown in Table 4. After correlating these values of rate constants with the temperature history (Table 4), the activation as well as the pre-exponential factors (Figure 4) were obtained. Using Equation 18, the order 
of reaction (n) for pine needle samples was obtained, while thermal parameters obtained by DSC curves in Figure 2 (c) are shown in Table 5.

Table 4. Kinetic parameters for pine needle pyrolysis in an inert atmosphere of nitrogen

\begin{tabular}{|c|c|c|c|c|c|c|c|c|}
\hline $\begin{array}{l}\text { Sample } \\
\text { number }\end{array}$ & $\begin{array}{r}\text { (Ac } \\
\text { energy }\end{array}$ & $\begin{array}{l}\mathrm{E} \\
\text { vation } \\
(\mathrm{kJ} / \mathrm{mol})\end{array}$ & (Pre-expor & $\begin{array}{l}\text { tial factor) } \\
\text { 1) }\end{array}$ & $\begin{array}{l}\text { Sample } \\
\text { number }\end{array}$ & $\begin{array}{c}\text { Temper } \\
\text {-ature } \\
\text { Range } \\
\left({ }^{\circ} \mathrm{C}\right)\end{array}$ & $\begin{array}{c}\mathbf{k}_{\mathrm{v}}\left(\mathbf{s}^{-1}\right) \\
\text { (firstorder } \\
\text { model) }\end{array}$ & $\begin{array}{l}\mathbf{k}_{\mathbf{s}}\left(\mathbf{s}^{-1}\right) \\
(\mathrm{SCM})\end{array}$ \\
\hline \multirow{4}{*}{$\begin{array}{l}\text { Sample } 1 \\
\text { (Teri) }\end{array}$} & \multirow{2}{*}{$\mathrm{SCM}$} & \multirow{2}{*}{$\begin{array}{l}\text { Model- } \\
\text { free }\end{array}$} & \multirow{2}{*}{ SCM } & \multirow{2}{*}{ Model-free } & \multirow{4}{*}{ Sample 1} & 300 & $4.53 \mathrm{E}-04$ & $1.94 \mathrm{E}-04$ \\
\hline & & & & & & 350 & $6.88 \mathrm{E}-04$ & $2.42 \mathrm{E}-04$ \\
\hline & 3221 & 2260 & 1274105 & $108 E-06$ & & 400 & $8.63 \mathrm{E}-04$ & 2.64E-04 \\
\hline & & & & & & 450 & $1.03 \mathrm{E}-03$ & 2.79E-04 \\
\hline \multirow{4}{*}{$\begin{array}{l}\text { Sample } 2 \\
\text { (Rishikesh) }\end{array}$} & \multirow{4}{*}{40.55} & \multirow{4}{*}{23.64} & \multirow{4}{*}{6555.10} & \multirow{4}{*}{$9.37 \mathrm{E}-07$} & \multirow{4}{*}{ Sample 2} & 300 & $3.26 \mathrm{E}-04$ & $1.44 \mathrm{E}-04$ \\
\hline & & & & & & 350 & $5.78 \mathrm{E}-04$ & $2.43 \mathrm{E}-04$ \\
\hline & & & & & & 400 & 7.74E-04 & $2.69 \mathrm{E}-04$ \\
\hline & & & & & & 450 & $9.78 \mathrm{E}-04$ & $2.86 \mathrm{E}-04$ \\
\hline \multirow{4}{*}{$\begin{array}{l}\text { Sample } 3 \\
\text { (Champawat) }\end{array}$} & \multirow{4}{*}{34.52} & \multirow{4}{*}{22.61} & \multirow{4}{*}{2197.33} & \multirow{4}{*}{$1.145 \mathrm{E}-06$} & \multirow{4}{*}{ Sample 3} & 300 & $3.93 \mathrm{E}-04$ & $1.86 \mathrm{E}-04$ \\
\hline & & & & & & 350 & $6.10 \mathrm{E}-04$ & $2.30 \mathrm{E}-04$ \\
\hline & & & & & & 400 & 8.43E-04 & $2.66 \mathrm{E}-04$ \\
\hline & & & & & & 450 & $1.01 \mathrm{E}-03$ & $2.80 \mathrm{E}-04$ \\
\hline
\end{tabular}

Table 5. Order of reaction and thermal parameters of samples (DSC curves) in an inert atmosphere

\begin{tabular}{lccc}
\hline \multicolumn{1}{c}{$\begin{array}{c}\text { Sample } \\
\text { Number }\end{array}$} & $\begin{array}{c}\text { Order of } \\
\text { reaction }(\mathbf{n})\end{array}$ & $\begin{array}{c}\text { Specific heat } \\
\left(\mathbf{C}_{\mathbf{p}}\right)\end{array}$ & $\begin{array}{c}\Delta \mathbf{H} \\
\text { (Net heat content) }\end{array}$ \\
\hline $\begin{array}{l}\text { Sample 1 } \\
\text { (Teri) }\end{array}$ & 0.32 & $22.5 \mathrm{~kJ} / \mathrm{kg} \mathrm{K}$ & $0.262 \mathrm{~kJ}$ \\
\hline $\begin{array}{l}\text { Sample 2 } \\
\text { (Rishikesh) }\end{array}$ & 0.37 & $28.26 \mathrm{~kJ} / \mathrm{kg} \mathrm{K}$ & $0.2181 \mathrm{~kJ}$ \\
\hline $\begin{array}{l}\text { Sample 3 } \\
\text { (Champawat) }\end{array}$ & 0.21 & $36.18 \mathrm{~kJ} / \mathrm{kg} \mathrm{K}$ & $0.2256 \mathrm{~kJ}$ \\
\hline
\end{tabular}

The lower value of the parameter $\mathrm{n}$ (order of reaction) implies the strong inhibiting effects of nitrogen on the pyrolytic decomposition of loose biomass (pine needles). The activation energy and other parameters, especially by the shrinking core model, are in accordance with the earlier research experiment [59]. The lower value of the order of reaction in nitrogen was found to be the same by various methods that were discussed by Volvella et al. [60] 


\section{Conclusion and discussion}

Needle samples obtained from the forest areas of Uttarakhand underwent a pyrolysis in a thermo-balance with an inert atmosphere of $\mathrm{N}_{2}$ in order to study the thermal behaviour of loose biomass within the temperature range of 19 to $600^{\circ} \mathrm{C}$ at ramping rate of $10^{\circ} \mathrm{C} / \mathrm{min}$. The thermogravimetric experiments performed in a dynamic mode showed that the reactivity of pine needle samples was inhibited by nitrogen at a higher temperature. Moreover, decomposition rate with nitrogen was slower than that of the air or carbon dioxide, and transformation occured at very higher temperatures $\left(>350^{\circ} \mathrm{C}\right)$. Most of the transformation occurs in a relatively narrow range of temperatures, which is different for each gas [61]. To understand the behaviour of loose biomass (pine needles), various models have been used to study the pyrolysis of biomass (viz. Two consecutive reaction schemes, Momentum equation for motion of pyrolysis gases, etc.). In this study, the simplest form of kinetics models for solid-gas reaction (the first-order model and the shrinking core model) has been implemented to find the better-fitting model for predicting the kinetic of chemical reaction during pyrolysis of loose biomass. The model-free method was only used to compare the values of activation energies and the preexponential function with the shrinking core model in order for a comprehensive study of the kinetics of loose biomass with other prevailing models. From all the results, it was concluded that the shrinking core model for the reaction-controlled regime predicted well for the rate of pyrolysis up to $95 \%$ conversion in nitrogen, whereas this was only $85 \%$ with the first-order reaction model. Activation energies (E) and the pre-exponential factors (A) were evaluated for both model-free and SCM. In addition, the order of reaction with respect to conversion rate was determined. In this kinetic study, the calculated kinetic parameters are within the range of values which were previously reported in the literature of the pyrolysis process of biomass [60].

\section{References}

[1] Kala, C., P., (2004), Indigenous uses and structure of chir pine forest in Uttaranchal, Himalaya, India. International Journal of Sustainable \& World Ecology 11(2), 205-210.

[2] Merila, P., Derome, J. (2008), Relationship between needle nutrient composition in Scots pine and Norway spruce and their respective concentrations in the organic layer and in percolation water. Boreal Env. Research 13 (suppl. B), 35-47.

[3] Dhaundiyal, A., Gupta, V. K. (2014), Analysis of pine needles as a substrate for gasification. Journal of Water, Energy and Environment 15, 73-81.

[4] Lv, P., Wu, C., Ma, L., Yuan, Z. (2008), A study on the economic efficiency of hydrogen production from biomass residues in china. Renewable Energy 33(1), 1874-1879.

[5] Kendry, M. (2002), Energy production from biomass (part 1): overview of biomass. Bioresource Technology 83, 37-46. 
[6] Szczodrak, J., Fiedurek, J. (1996), Technology for conversion of lignocellulosic biomass to ethanol. Biomass Bioenergy 49(2), 367-375.

[7] White, J. E., Catallo, W. J., Legendra, B. L. (2011), Biomass pyrolysis kinetics: a comparative critical review with relevant agricultural residue case studies. Journal of Analytical and Applied Pyrolysis 91(1), 1-33.

[8] Ghetti, P., Ricca, L., Angelini, L. (1996), Thermal analysis of biomass and corresponding pyrolysis products. Fuel 75(5), 565-573.

[9] Seo, D. K., Park, S. S., Junghoyu, T. U. (2010), Study of the pyrolysis of biomass using thermo-gravimetric analysis (tga) and concentration measurements of the evolved species. Journal of Analytical and Applied Pyrolysis 89(1), 66-73.

[10] Giuntoli, J., De Jong, W., Arvelakis, S., Spliethoff, H., Verkooijen, A. H. M. (2009), Quantitative and kinetic TG-FTIR study of biomass residue pyrolysis: dry distiller's grains with solubles (ddgs) and chicken manure. Journal of Analytical and Applied Pyrolysis 85(1), 301-312.

[11] Lapuerta, M., Hernández, J. J., \& Rodríguez, J. (2004), Kinetics of devolatilisation of forestry wastes from thermogravimetric analysis. Biomass and Bioenergy 27(1), 385-91.

[12] Zhu, H. M., Yan, J. H., Jiang, X. G., Lai, Y. E., Cen, K. F. (2009), Analysis of volatile species kinetics during typical medical waste materials pyrolysis using a distributed activation energy model. Journal of Hazardous Materials 162(2), 646-651.

[13] Folgueras, M. B., Díaz, R. M., Xiberta J., Prieto, I. (2003), Thermogravimetric analysis of the co-combustion of coal and sewage sludge. Fuel 82, 1051-1055.

[14] Otero, M., Calvo, L. F., Gil, M. V., García, A. I., Morán, A. (2008), Combustion of different sewage sludge and coal: a nonisothermal thermogravimetric kinetic analysis. Bioresource Technol 99, 6311-6319.

[15] Koreòová, Z., Juma, M., Annus, J., Markoš, J., Jelemenský, L. (2006), Kinetics of pyrolysis and properties of carbon black from a scrap tire. Chemical Papers 60, 422.

[16] Stenseng, M., Jensen, A., Dam-Johansen, K. (2001), Investigation of biomass pyrolysis by thermogravimetric analysis and differential scanning calorimetry. Journal of Analytical and Applied Pyrolysis 765, 58-59.

[17] Di Blasi, C. (2008), First principal modeling of the pyrolysis of a thick biomass slab exposed to thermal radiation: a transient study for tar, char and hydrocarbon formation progress. Energy and combustion science 34(5), 47-90.

[18] Aboyade, A. O., Hugo, T. J., Carrier, M., Meyer, E. L., Stahl, R., Knoetze, J. H., Görgens, J. F. (2011), Non-isothermal kinetic analysis of corn cobs and sugar cane bagasse pyrolysis. Thermochimica Acta 517, 81-89.

[19] Šimon, P. (2004), Isoconversional methods fundamentals, meaning and application. Journal of Thermal Analysis and Calorimetry 76, 123-132.

[20] Nowicki, L., Stolarek, P., Olewski, T., Bedyk, T., Ledakowicz, S. (2008), Mechanism and kinetics of sewage sludge pyrolysis by thermogravimetry and mass spectrometry analysis. Chemical and Process Engineering 29, 813-825.

[21] Cetin, E., Moghtaderi, B., Gupta, R., Wall, T. F. (2004), Influence of pyrolysis conditions on the structure and gasification reactivity of biomass chars. Fuel 83, 2139-2150.

[22] Di Blasi, C. (2009), Combustion and gasification rates of lignocellulosic chars, Progr. Energy Comb. Sci. 35, 121-140.

[23] Santacesaria, E. (1999), Fundamental chemical kinetics: the first step to reaction modelling and reaction engineering. Catal Today, 113-123.

[24] Prakash, N., Karunanithi, T. (2008), Kinetic modeling in biomass pyrolysis. A review. Journal of Applied Sciences Research 4, 1627-1636.

[25] Fisher, T., Hajaligol, M., Waymack, B., Kellogg, D. (2002), Pyrolysis behavior and kinetics of biomass derived materials. Journal of Analytical and Applied Pyrolysis 62, 331-349. 
[26] Kilzer, F. J., Broido, A. (1965), Speculation on the nature ofcellulose pyrolysis. Pyrodynamics $2,151-163$.

[27] Antal, M. J., Jr., Varhegyi, G. (1995), Cellulose pyrolysis kinetics: the current state of knowledge. Industrial and Engineering Chemistry Research 34, 703-717.

[28] Varhegyi, G., Antal, M. J., Jr., Jakab, E., Szabo, P. (1997), Kinetic modeling of biomass pyrolysis. Journal of Analytical Pyrolysis 42, 73-87.

[29] Varhegyi, G., Jakab, E., Antal, M. J. (1994), Is the broido-shafizadeh model for cellulose pyrolysis true? Energy \& Fuels 8, 1345-1352.

[30] Banyasz, J. L., Li, S., Lyons-Hart, J., Shafer, K. H. (2001a), Cellulose pyrolysis: the kinetics of hydroxyacetaldehyde evolution. Journal of Analytical and Applied Pyrolysis 57(2), 223-248.

[31] Li, S., Lyons-Hart, J., Banyasz, J. L., Shafer, K. H. (2001), Real-time evolved gas analysis by FTIR method: an experimental Study of cellulose pyrolysis. Fuel 80, 1809-1817.

[32] Mamleev, V., Bourbigot, S., Yvon, J. (2007), Kinetic analysis of the thermal decomposition of cellulose: the change of the Rate limitation. Journal of Analytical and Applied Pyrolysis 80, 141-150.

[33] Broido, A., Weinstein, M. (1972), Low temperature isothermal pyrolysis of cellulose. Thermal analysis, 285-296.

[34] Bradburry, A. G. W., Sakai, Y., Shafizadeh, F. (1979), A kinetic model for pyrolysis of cellulose. Journal of Applied Polymer Science 23, 3271-3280.

[35] Vyazovkin, S., Dollimore, D. (1996), Linear and nonlinear procedures in isoconversional computations of the activation. Energy of nonisothermal reactions in solids. Journal of Chemical Information and Modeling 36, 42-45.

[36] Flynn, J. H. (1997), The 'temperature integral' - its use and abuse. Thermochimica Acta 300, $83-92$.

[37] Friedman, H. L. (1964), Kinetics of thermal degradation of charforming plastics from thermogravimetry. Application to a Phenolic plastic. Journal of Polymer Science Part C: Polymer Symposia 6, 183-195.

[38] Vyazovkin, S., Burnham, A. K., Criado, J. M., Perez-Maqueda, L. A., Popescu, C., Sbirrazzuoli, N. (2011), ICTAC Kinetics Committee recommendations for performing kinetic computations on thermal analysis data. Thermochimica Acta 520, 1-19.

[39] Brown, M. E., Maciejewski, M., Vyazovkin, S., Nomen, R., Sempere, J., Burnham, A., Opfermann, J., Strey, R., Anderson, H. L., Kemmler, A., Keuleers, R., Janssens, J., Desseyn, H. O., Li, C. R., Tang, T. B., Roduit, B., Malek, J., Mitsuhashi, T. (2000), Computational aspects of kinetic analysis: part a: the ICTAC kinetics project-data, methods and results. Thermochimica Acta 355, 125-143.

[40] Yagi, S., Kunii, D. (1955), In: Proc. $5^{\text {th }}$ Int. Symp. On combustion. Journal of Analytical and Applied Pyrolysis 42.

[41] Sohn, H. Y., Wadsworth, M. E. (1979), Rate processes of extractive metallurgy. Plenum press, New York.

[42] Levenspiel, O. (1972), Fluid-particle reactions. In: chemical reaction engineering, $2^{\text {nd }}$ ed. pp. 357-400. John Wiley \&Sons, Singapore.

[43] Szekely J., Ewans, J. W., Sohn H. I. (1976), Gas-solid reactions. New York: Academic Press.

[44] Vallet, P. (1961), Tables numkriques permettant l'integration des constantes de francais, anglais, espagnol). Vitesse par rapport a la temperature (texte trilingue: Gauthier-Villars, Paris).

[45] Hollagh, A. R. E., Alamdari, E. K., Moradkhani, D., Salardini A. A. (2013), Kinetic analysis of isothermal leaching of zinc from zinc plant residue. International Journal of Nonferrous Metallurgy 2, 10-20.

[46] Gašparovič, L., Koreňová, Z., Jelemenský, L. (2009), Kinetic study of wood chips decomposition, $36^{\text {th }}$ International conference of SSCHE, May 25-29. 
[47] Bedyk, T., Nowicki, L., Stolarek, P., Ledakowicz, S. (2009), Effect of cao and dolomite additive in the thermal decomposition of sewage sludge in an inert atmosphere. J. Residuals Sci. Technol. 6(1), 3-10.

[48] Milosavljevic, I., Suuberg, E. M. (1995), Cellulose thermal decomposition kinetics: global mass loss kinetics. Ind. Eng. Chem. Res 34, 1081-1091.

[49] Bilbao, R., Mastral, J. F., Aldea, M. E., Ceamanos, J. (1997), Kinetic study for the thermal decomposition of cellulose and pine sawdust in an air atmosphere. J. Anal. Appl. Pyrol. 39, 53-64.

[50] Baker, R. R. (1978), Kinetic parameters from the non-isothermal decomposition of a multicomponent solid. Thermochim Acta 23(2), 201-212.

[51] Encinar, J. M., Gonzalez, J. F., Gonzalez, J. (2000), Fixed-bed pyrolysis of cynara cardunculus 1. Product yields and compositions fuel process. Technol 68, 209-222.

[52] Shafizadeh, F. (1982), Introduction to pyrolysis of biomass. J. Anal. Appl. Pyrolysis 3, 283-305.

[53] Zanzi, R. (2001), Pyrolysis of biomass, dissertation, royal institute of technology, department of chemical engineering and technology, Stockholm.

[54] Zanzi, R., Sjosyrom, K., Bjombom E. (2002), Rapid pyrolysis of agricultural residues at high temperature. Biomass Bioenergy 23(5), 356-366.

[55] Steve Aston, Stefan Doerr, Alayne Street-P. (2013), The impacts of pyrolysis temperature and feedstock type on biochar properties and the effects of biochar application on the properties of a sandy loam. Geophysical Research Abstracts, vol. 15, EGU2013-11083, Egu General Assembly 2013.

[56] Gustsfsoon, C., Richards, T. (2009), Pyrolysis kinetics of washed precipitated lignin. Bio resources 4(1), 26-37.

[57] Caballero, J. A., Font, R., Marcilla, A. (1996), Study of primary pyrolysis of kraft lignin at high heating rates: yields and kinetics. Journal of Analytical and Applied Pyrolysis 36(2), 159-178.

[58] Lee, C. K., Chaiken R. F., Singer, J. M. (1976), Charring pyrolysis of wood in fires by laser simulation. $16^{\text {th }}$ Symposium (Intl.) on Combustion, Combustion Institute, Pitts, pp. 1459-1470.

[59] Lopez Pasquali, C. E., Herrera, H. (1997), Pyrolysis of ligin and ir analysis of residues. Thermochimica Acta 293(1-2), 39-46.

[60] Vovelle, C., Mellottee, H., Delbourgo, R. (1983), Kinetics of thermal degradation of wood and cellulose by T.G.A. comparison of the calculation techniques. Am. Chem. Soc., Div. Fuel Chem.; (United States); journal volume: 28:5; conference: 186. National meeting of the American Chemical Society, Washington, DC, USA. http://web.anl.gov/pcs/acsfuel/preprint \%20archive/files/28_5_washington\%20dc_08-83_0291.pdf

[61] Órfão, J. J. M., Antunes F. J. A, Figueiredo, J. L. (1999), Pyrolysis kinetics of lignocellulosic materials three independent reactions model. Fuels 78, 349-358. 